\title{
Biomarkers of Coagulation, Inflammation, and Angiogenesis are Independently Associated with Preeclampsia
}

Roland Boij, Judit Svensson, Kristina Nilsson-Ekdahl, Kerstin Sandholm, Tomas Lindahl, Elzbieta Palonek, Mats Garle, Göran Berg, Jan Ernerudh, Maria Jenmalm and Leif Matthiesen

\section{Linköping University Post Print}

N.B.: When citing this work, cite the original article.

Original Publication:

Roland Boij, Judit Svensson, Kristina Nilsson-Ekdahl, Kerstin Sandholm, Tomas Lindahl, Elzbieta Palonek, Mats Garle, Göran Berg, Jan Ernerudh, Maria Jenmalm and Leif Matthiesen, Biomarkers of Coagulation, Inflammation, and Angiogenesis are Independently Associated with Preeclampsia, 2012, AMERICAN JOURNAL OF REPRODUCTIVE IMMUNOLOGY, (68), 3, 258-270.

http://dx.doi.org/10.1111/j.1600-0897.2012.01158.x

Copyright: John Wiley and Sons http://www.wiley.com/

Postprint available at: Linköping University Electronic Press

http://urn.kb.se/resolve?urn=urn:nbn:se:liu:diva-81815 


\section{Introduction}

Preeclampsia is a major obstetric problem causing maternal and fetal morbidity and mortality, affecting 2-8 percent of the pregnant population worldwide (1) .

There is still no generally accepted etiology of preeclampsia, but an increasing body of evidence indicates that involvement of the immune system with a defective tolerance to the conceptus is an integral part of the pathogenesis (2-4). Preeclampsia seems to be a heterogeneous syndrome with or without obvious placental pathology and studies on the pathogenesis and biomarkers of preeclampsia have not shown entirely consistent findings. Preeclampsia can be divided into early onset (EOP) or late onset preeclampsia (LOP), depending on whether the onset of the syndrome was before or after completed gestational week 32, although 34 weeks is sometimes used (5). EOP is associated with low birth weight and underlying placental abnormality, while LOP may represent a syndrome with a mixture of conditions, ranging from mild preeclampsia with moderate placental affection to hypertensive conditions in pregnancy without placental dysfunction $(6,7)$.

Although many studies have demonstrated the involvement of coagulation, inflammation and angiogenesis in the pathogenesis of preeclampsia, most of them have focused on only one of these aspects and studies have mostly been rather small $(5,8-12)$. The relative importance of these mechanisms and the correlation between them are thus not fully defined. Furthermore, the impact of gestational and maternal age, start of labor or maternal cortisone treatment has not sufficiently been taken into account and subgroup analyses for EOP and LOP, which may have different pathogenesis, are frequently lacking.

Our hypothesis was that coagulation, inflammation and angiogenesis are all involved and correlated in the pathogenesis of preeclampsia. The aim of this study was to assess if this involvement and correlation existed in EOP and LOP by studies on a broad panel of biological markers in a large sample of pregnant women. 


\section{Material and methods}

\section{Demographic background}

Approximately 10000 women gave birth each year during the study period from year 2004 until year 2006 in the Southeast region of Sweden. According to local obstetric registers, approximately $3 \%$ developed preeclampsia. $1 / 3$ of cases were severe and $2 / 3$ were mild. 0.2 $0.3 \%$ of these delivered at $<34$ weeks of pregnancy, an approximation for early onset preeclampsia. The annual number of deliveries during the time of the study was approximately 1800 at the County Hospital Ryhov in Jönköping and 2500 at the University Hospital in Linköping. Most cases (95\%) of preeclampsia were recruited from these hospitals. During the study period the total number of preeclampsia cases at these two hospitals was approximately 500 according to obstetric databases, corresponding to $3.8 \%$ of deliveries. This prevalence is based on the referral status of these hospitals; most women with preeclampsia before 36 weeks of pregnancy are transferred to these hospitals.

\section{Study group and control group}

In a group of 114 women from the region with the diagnosis of preeclampsia (see Table1), markers of the coagulation cascade, inflammation and angiogenesis were measured. The same measurements were done in a control group of 100 women with normal pregnancies. The sample size was assumed to be enough since most studies on biomarkers in preeclampsia were done with smaller samples and we wanted a large but not too time-consuming sample. No exact power calculation was done due to the amount of biomarkers included in the study. The preeclamptic women were recruited from the departments of obstetrics at the County Hospital Ryhov in Jönköping ( $\mathrm{n}=84)$, the University Hospital in Linköping $(\mathrm{n}=24)$ and the County Hospital in Kalmar ( $n=6)$. The control group was recruited from antenatal care centers and maternity ward in Jönköping $(n=63)$ and Linköping $(n=20)$ and from the maternity ward 
at the County Hospital Vrinnevi in Norrköping $(n=17)$. All four major hospitals in the region were thus involved.

Table 1 Clinical spectrum of preeclampsia cases (percentage within braclets).

\begin{tabular}{|l|l|l|l|l|l|}
\hline & SGA baby & HELLP syndrome & Eclampsia & Mild PE & Severe PE \\
\hline EOP $(n=31)$ & $14(45.2)$ & $7(22.6)$ & $1(3.2)$ & $6(19.4)$ & $25(80.6)$ \\
\hline LOP $(n=83)$ & $6(7.2)$ & $3(3.6)$ & $1(1.2)$ & $63(75.9)$ & $20(24.1)$ \\
\hline PE & $20(17.5)$ & $10(8.8)$ & $2(1.8)$ & $69(60.5)$ & $45(39.5)$ \\
\hline
\end{tabular}

$\mathrm{SGA}=$ Small for gestational age

$\mathrm{EOP}=$ early onset preeclampsia, $\mathrm{LOP}=$ late onset preeclampsia, $\mathrm{PE}=$ preeclampsia

HELLP= Hemolysis, Elevated Liver enzymes, Low Platelet count

Inclusion with information, informed consent and blood sampling was done during daytime soon after admission to hospital for preeclamptic women irrespective of gestational length.

For the control group, the women were included similarly when they appeared for their regular visits at antenatal care centers. Blood sampling was done by midwives and immediately sent to the laboratory for centrifugation, separation into plasma and blood samples and storing in a freezer.

Women with diabetes, kidney diseases, multiple pregnancies and essential hypertension were excluded and so were women on anticoagulant or steroid medication before pregnancy. Two cases were excluded from the control group due to fetal growth restriction and fetal death. In the preeclampsia group, 4 women were excluded due to diabetes, 6 due to twin pregnancy, 1 due to pregnancy-induced hypertension, 1 due to systemic lupus erythematosus (SLE) with steroid medication and 1 due to prophylactic treatment with low molecular weight heparin (LMWH) during pregnancy. Preeclampsia was defined as new onset of proteinuric hypertension after 20 weeks of gestation. Mild and severe preeclampsia diagnosis was made according to American Congress of Obstetricians and Gynecologists (ACOG) (13). 
Preeclampsia was defined as EOP when onset was before and LOP when onset was after 32 gestational weeks (5). For the clinical spectrum of preeclampsia, see table 1.

The control group was matched for maternal and gestational age. The mean gestational age in the index group was 35.7 weeks compared to 34.3 weeks in the control group. The mean age was 29.8 years in the index group and 30.2 in the control group. None of these differences were significant.

\section{Blood sampling}

The blood samples were drawn into EDTA and Na-citrate tubes. For isolation of plasma blood samples were centrifuged within $1 \mathrm{~h}$ after sampling, blood and plasma samples were immediately frozen and stored at $-70{ }^{\circ} \mathrm{C}$ until analyzed at the laboratory at the University Hospital in Linköping except for complement measurements, which were done at a laboratory at the Linneaus University in Kalmar, and cortisone measurements, which were done at the Doping Control Laboratory, Karolinska University Hospital, Huddinge, Stockholm.

\section{Coagulation tests}

Analysis was done for protein C, protein S, antithrombin (AT), factor V Leiden mutation (FVL), prothrombin gene mutation, fibrinogen, lupus anticoagulant, cardiolipin antibodies, Prothrombine Time (PT) measured as International Normalized Ratio (INR), Activated Partial Thromboplastin Time (APTT), D-Dimer and platelets. All coagulation analyses were performed on citrated plasma (1/10 volume $0.13 \mathrm{~mol} / \mathrm{L}$ citrate) on an automated coagulation instrument, ACL Top (IL, Milan, Italy) except D-dimer, which was performed by an immunoturbidometric method on a clinical chemistry instrument, Advia 1650, purchased from Bayer Sweden (Gothenburg, Sweden). For protein C and antithrombin a chromogenic and for protein $\mathrm{S}$ an immunoturbidometic method was used. DNA-analysis was performed by pyrosequencing on a PSQ HS 96A System (Biotage, Uppsala, Sweden) (14) and platelet 
counting was done with a particle counter Abbot Celldyn 3200 on blood anticoagulated with

EDTA. APTT, fibrinogen and lupus anticoagulant were analyzed by clotting methods on ACL

Top and cardiolipin antibodies by ELISA.

For reference ranges, see table 2.

Table 2 Coagulation factors

\begin{tabular}{|c|c|c|c|c|}
\hline Test & $\begin{array}{l}\text { Reference } \\
\text { range }\end{array}$ & EOP & LOP & $\begin{array}{l}\text { Controls } \\
\text { (normal } \\
\text { pregnancy) }\end{array}$ \\
\hline protein $\mathrm{C}$ & $\begin{array}{l}0.70-1.4 \\
\mathrm{kIE} / \mathrm{L}\end{array}$ & $\begin{array}{l}0.93 * \\
(0.80-1.06) \\
\end{array}$ & $\begin{array}{l}1.05 \\
(0.98-1.12) \\
\end{array}$ & $\begin{array}{l}1.10 \\
(1.04-1.15)\end{array}$ \\
\hline protein $\mathrm{S}$ & $\begin{array}{l}0.57-1.3 \\
\mathrm{kIE} / \mathrm{L}\end{array}$ & $\begin{array}{l}0.52 \\
(0.48-0.59)\end{array}$ & $\begin{array}{l}0.50 \\
(0.46-0.53)\end{array}$ & $\begin{array}{l}0,52 \\
(0.48-0.56)\end{array}$ \\
\hline antithrombin & $\begin{array}{l}0.85-1.25 \\
\mathrm{kIE} / \mathrm{L}\end{array}$ & $\begin{array}{l}0.76 * * * \\
(0.70-0.81)\end{array}$ & $\begin{array}{l}0.86 * * * \\
(0.82-0.90)\end{array}$ & $\begin{array}{l}0.97 \\
(0.94-1.00)\end{array}$ \\
\hline $\begin{array}{l}\text { factor V } \\
\text { Leiden } \\
\text { mutation }\end{array}$ & $\begin{array}{l}\text { normal/hete } \\
\text { ro-zygote } \\
\text { /homo- } \\
\text { zygote }\end{array}$ & $\begin{array}{l}9 / 30^{*} \\
\text { heterozyg. } \\
0 \text { homozyg. }\end{array}$ & $\begin{array}{l}9 / 76 \\
\text { heterozyg. } \\
0 \text { homozyg. }\end{array}$ & $\begin{array}{l}9 / 70 \\
\text { heterozyg. } \\
0 \text { homozyg. }\end{array}$ \\
\hline fibrinogen & $2.0-4.0 \mathrm{~g} / \mathrm{L}$ & $\begin{array}{l}4.8 \\
(4.2-5.5)\end{array}$ & $\begin{array}{l}5.2 \\
(4.9-5.4)\end{array}$ & $\begin{array}{l}5.4 \\
(4.3-6.3)\end{array}$ \\
\hline $\begin{array}{l}\text { lupus } \\
\text { anticoagulant }\end{array}$ & $\begin{array}{l}\text { negative } \\
\text { /positive }\end{array}$ & $\begin{array}{l}8 \text { positive } \\
30 \text { negative }\end{array}$ & $\begin{array}{l}20 \text { positive } \\
52 \text { negative }\end{array}$ & $\begin{array}{l}17 \text { positive } \\
32 \text { negative }\end{array}$ \\
\hline $\begin{array}{l}\text { cardiolipin } \\
\text { antibodies }\end{array}$ & $<10$ & all $<10$ & all $<10$ & all $<10$ \\
\hline PT/INR & $0.9-1.2$ & $\begin{array}{l}0.93 \\
(0.87-0.99)\end{array}$ & $\begin{array}{l}0.87 \\
(0.85-0.0 .89)\end{array}$ & $\begin{array}{l}0.89 \\
(0.86-0.91)\end{array}$ \\
\hline APTT & $24-34 \mathrm{~s}$ & $\begin{array}{l}29.3 \\
(27.9-30.8)\end{array}$ & $\begin{array}{l}29.8 \\
28.8-30.8 \\
\end{array}$ & $\begin{array}{l}30.6 \\
(29.6-31.6)\end{array}$ \\
\hline D-Dimer & $<0.25$ & $\begin{array}{l}1.35^{*} \\
(0.64-2.07)\end{array}$ & $\begin{array}{l}0.66 \\
(0.51-0.81)\end{array}$ & $\begin{array}{l}0.48 \\
(0.38-0.59)\end{array}$ \\
\hline platelets & $\begin{array}{l}150-400 \times \\
109 / \mathrm{L}\end{array}$ & $\begin{array}{l}189 * \\
(159-219)\end{array}$ & $\begin{array}{l}205^{*} \\
(191-218)\end{array}$ & $\begin{array}{l}251 \\
(216-285)\end{array}$ \\
\hline
\end{tabular}

Means and $95 \% \mathrm{CI}$ indicated.

PT=Prothrombine Time, INR= International Normalized Ratio, APTT=Activated Partial Thromboplastin Time

$* \mathrm{p}<0.05, * * \mathrm{p}<0.01, * * * \mathrm{p}<0.001$ vs controls. Parametric t-test used. 


\section{Complement components and activation products}

The complement components $\mathrm{C} 3$ and factor $\mathrm{H}$ and the activation products $\mathrm{C} 3 \mathrm{a}$ and sC5b-9 complex were measured by sandwich ELISA. For the C3a assay, diluted plasma was incubated in wells coated with monoclonal antibody 4SD17.3 and C3a was detected using a biotinylated polyclonal anti-human C3a antibody, followed by horse radish peroxidase (HRP)-conjugated streptavidin (GE Healthcare, Buckinghamshire, UK (15)

Detection of sC5b-9 in plasma was performed as described previously (16). Diluted plasma was added to wells coated with anti-neoC9 monoclonal antibody aE11 (Diatec Monoclonals AS, Oslo, Norway). SC5b-9 was detected with a polyclonal anti-human C5 antibody (Dako, Glostrup, Denmark), followed by HRP-conjugated anti-rabbit immunoglobulin (Dako). In the C3a and sC5b-9 assays, zymozan-activated serum calibrated against a known C3a and sC5b-9 concentration, was used as a standard. In each determination a control of pooled plasma was included.

The C3 assay plates were coated with anti-human C3c antibody (Dako), which recognizes C3, $\mathrm{C} 3 \mathrm{~b}, \mathrm{iC} 3 \mathrm{~b}$, and C3c. Detection of the bound C3/C3-fragments was carried out with biotinylated anti-C3c antibody, followed by streptavidin-HRP (GE Healthcare) (17). For factor $\mathrm{H}$ determination, microtiter plates were coated with anti-human factor $\mathrm{H}$ antibody (PC 030, Binding Site, Birmingham, UK), and detection of bound factor $\mathrm{H}$ was performed using a mixture of biotinylated and non-labeled anti-human factor $\mathrm{H}$ antibody. In each determination of $\mathrm{C} 3$ and factor $\mathrm{H}$, a sample with known concentrations of $\mathrm{C} 3$ and factor $\mathrm{H}$ was used as a standard. Pooled plasma was used as a control in each analysis. DeltaSoft (BioMetallics Inc, Princeton NJ, USA) software was used to determine the concentration of $\mathrm{C} 3 \mathrm{a}, \mathrm{sC} 5 \mathrm{~b}-9, \mathrm{C} 3$ and factor $\mathrm{H}$ in each sample (15-17). All values were above detection limit. 


\section{Cytokines}

The cytokine levels were determined by multiplex bead array. The levels of Granulocyte Macrophage-Colony Stimulating factor (GM-CSF), Interferon-gamma (IFN- $\gamma$ ), interleukin1 beta (IL-1 $\beta$ ), IL-2, IL-4, IL-5, IL-6, IL-8, IL-10 and Tumor Necrosis Factor (TNF) were measured in plasma using the ultrasensitive multiplex kit LHC 6004 (Invitrogen, Camarillo, CA, USA) according to the manufacturer's protocol, except that an additional lower standard point was added to the standard curve by serial dilution and the highest standard point was not included. The levels of M-CSF were measured with a Milliplex ${ }^{\circledR}$ MAP kit (Millipore Corporation, Billerica, MA, USA) according to the manufacturer's instructions. The analyses were performed using the Luminex 100® IS system (Luminex Corporation, Austin, Texas, USA) and the StarStation IS software (V2.3, Applied Cytometry Systems, Sheffield, UK). The lower detection limits (and within brackets the proportion of samples with values above the detection limits) were $0.75 \mathrm{pg} / \mathrm{ml}$ for GM-CSF (100\%), $0.71 \mathrm{pg} / \mathrm{ml}$ for IFN- $\gamma(100$ $\%), 0.13 \mathrm{pg} / \mathrm{ml}$ for IL-1 $(92.2 \%), 1.4 \mathrm{pg} / \mathrm{ml}$ for IL-2 (99.5\%), $1.4 \mathrm{pg} / \mathrm{ml}$ for IL-4 (100\%), $0.42 \mathrm{pg} / \mathrm{ml}$ for IL-5 (100\%), $0.56 \mathrm{pg} / \mathrm{ml}$ for IL-6 (100\%), $0.65 \mathrm{pg} / \mathrm{ml}$ for IL-8 (100\%), 0.15 $\mathrm{pg} / \mathrm{ml}$ for IL-10 (100\%), $0.51 \mathrm{pg} / \mathrm{ml}$ for TNF (100\%) and $98 \mathrm{pg} / \mathrm{ml}$ for M-CSF(17\%). Values below the detection limit were given half the value of the detection limit.

\section{Chemokines}

The levels of C-X-C motif chemokine 10 (CXCL10), CXCL11, C-C motif ligand 17 (CCL17) and CCL22 were measured with an in-house multiplexed Luminex assay as previously described (18), and analyzed on a Luminex100 instrument (Biosource, Nivelles, Belgium). All data was acquired using the Star Station 2.3 software (Applied cytometry systems, Sheffield, UK). The lower detection limits (and within brackets the proportion of samples with values above the detection limits) were $5.5 \mathrm{pg} / \mathrm{mL}$ for CXCL10 (100\%), $13.7 \mathrm{pg} / \mathrm{mL}$ for CXCL11 (100\%), $1.9 \mathrm{pg} / \mathrm{mL}$ for CCL17 (96,6\%) and 
$1.9 \mathrm{pg} / \mathrm{mL}$ for CCL22 (100\%). Values below the detection limit were given half the value of the detection limit.

\section{Soluble fms-like thyrosine kinase (sFIt-1), Placental Growth Factor (PIGF) and pentraxin-3}

Plasma samples were analyzed using DuoSet ELISA reagents from R\&D Systems (Abingdon, UK) for sFlt-1 (art no DY321), PlGF (art no DY264) and pentraxin-3 (art no DY1826). Highbinding ELISA plates (Costar 3590, Life Technologies, Täby, Sweden) were coated with 100 $\mu \mathrm{L} /$ well of $4 \mu \mathrm{g} / \mathrm{ml}$ monoclonal anti-human sFlt-1, $4 \mu \mathrm{g} / \mathrm{ml}$ monoclonal anti-human PlGF or 1 $\mu \mathrm{g} / \mathrm{ml}$ monoclonal anti-human pentraxin-3, diluted in carbonate buffer, $\mathrm{pH}$ 9.6. The plates were incubated overnight at room temperature and then blocked for $60 \mathrm{~min}$ in room temperature using $300 \mu \mathrm{L} /$ well of $1 \%$ bovine serum albumin (BSA, Sigma-Aldrich, Stockholm, Sweden) in $10 \mathrm{mM}$ phosphate buffered saline (PBS) $\mathrm{pH}$ 7.4. After washing four times with PBS-Tween using a microplate washer (Anthos microplate washer Fluido, Salzburg, Austria), standard curves with recombinant human sFlt-1, PlGF or pentraxin-3 were added, diluted in PBS with $1 \%$ BSA in seven two-fold steps. $100 \mu \mathrm{L}$ per well in duplicates was added of standard and samples (diluted at least 1:2) and incubated for two hours in room temperature. After washing, $100 \mu \mathrm{L} /$ well of $100 \mathrm{ng} / \mathrm{ml}$ biotinylated polyclonal goat-antihuman sFlt-1, $60 \mathrm{ng} / \mathrm{ml}$ biotinylated polyclonal goat-anti-human PlGF or $75 \mathrm{ng} / \mathrm{ml}$ biotinylated polyclonal goat-anti-human pentraxin-3, diluted in high-performance ELISA (HPE) buffer (CLB, Amsterdam, the Netherlands), was added and incubated for two hours in room temperature. After washing, 100- $\mu$ L streptavidin-poly-HRP (CLB), diluted 1/10,000 in HPE buffer was added to the wells. After 30 min on a plate shaker, the plates were washed and $100 \mu \mathrm{L}$ 3,3', 5,5'-tetramethylbenzidine liquid substrate system (Sigma-Aldrich) was added to each well and incubated on a plate shaker for $30 \mathrm{~min}$ in the dark. The reaction was terminated with $50 \mu \mathrm{L} 1.8 \mathrm{~m} \mathrm{H} 2 \mathrm{SO}$. The optical densities were read at $450 \mathrm{~nm}$ with a 
wavelength correction at $540 \mathrm{~nm}$ in a VersaMax tunable microplate reader (Molecular Devices, Sunnyvale, CA, USA). Data acquisition was performed using SoftMaxPro version 3.1.2 computer software (Molecular Devices). Values were expressed as $\mathrm{pg} / \mathrm{ml}$ deduced from the optical density of the standard curves after subtracting the blanks, using a 5-parameter logistic algorithm. Each sample was run in duplicate and a CV of maximum $15 \%$ was allowed. The lower detection limits (and within brackets the proportion of samples with values above the detection limits) were $39 \mathrm{pg} / \mathrm{ml}$ for sFlt-1 (100\%), $7.8 \mathrm{pg} / \mathrm{ml}$ for PlGF $(68.4 \%)$ and $7.8 \mathrm{pg} / \mathrm{ml}$ for pentraxin-3 (100\%). Values below the detection limit were given half the value of the detection limit.

\section{Cortisone (betamethasone, dexametasone and prednisolone)}

To confirm whether women with preeclampsia at the time point of blood sampling were or were not treated with cortisone, given to obtain fetal lung maturation, plasma samples from women with preeclampsia were measured for presence of cortisone at the Doping Control Laboratory, Karolinska University Hospital, Huddinge, Stockholm.

The method has been developed for routine analysis of corticosteroids in urine, both for screening and for confirmation (19). The Swedish Accreditation Body (SWEDAC) has accredited the method according to the standard ISO 17025.

Plasma samples were analyzed with the same method instrument described in the reference above, but plasma samples were treated first with acetonitrile to precipitate proteins. An internal standard mixture was prepared in acetonitrile at concentration of $50 \mathrm{ng} / \mathrm{mL}$ of methyltestosterone and $\mathrm{d}_{4}$-cortisol, respectively. A corticosteroid calibration mixture was prepared in plasma at a concentration of $120 \mathrm{ng} / \mathrm{mL}$. Two positive quality control (QC) mixtures were prepared in plasma at concentrations of $60 \mathrm{ng} / \mathrm{mL}$. Sample pre-treatment was done by adding $200 \mu \mathrm{L}$ of Acetonitrile solution (containing internal standards $50 \mathrm{ng} / \mathrm{mL}$ of methyltestosterone and $\mathrm{D}_{4}$-cortisol, respectively) to $50 \mu \mathrm{L}$ of plasma to precipitate proteins. 


\section{Statistical analysis}

Mann-Whitney nonparametric test was used to compare preeclamptic women with healthy controls except for coagulation factors (see table 2), where we used parametric test ( $\mathrm{t}$ test), since these factors were equally distributed.. Subgroup analysis was done for EOP and for LOP and women with EOP were also compared with women with LOP. We also compared women giving birth to SGA (small for gestational age) babies to women with AGA (appropriate for age) babies. Significance was defined as $\mathrm{p}<0.05$. Multivariate logistic regression test was done for the impact of gestational and maternal age, cortisone treatment, blood sampling during active labor or peripartal period for all biomarkers, since all these factors including timing of blood sampling could potentially affect the result. Blood analysis was done to indentify the women who had been treated recently with cortisone and in the multivariate logistic regression these cases were excluded since there were no cases with cortisone treatment in the control group. Time for blood sampling in relation to delivery was registered and cases with blood sampling within 2 days from delivery were controlled for in the multivariate logistic regression, since labour itself might influence the measured biomarkers. Subgroup analyses were done for EOP and LOP using the same statistical method. Chi2-test was used to compare occurrence of lupus anticoagulant or mutation for factor V Leiden between the PE group and the control group. Stratified analysis for parity was done for the women from Jönköping representing approximately $2 / 3$ of the included women. We did consider adjustment of the significance level based on the numerous comparisons but since we only report differences after multivariate logistic regression test we perceive that there is sufficient statistical certainty. Spearmans rank correlation test was used to analyze the correlations between coagulation, inflammation and angiogenesis by using the most significant marker within each group, i.e. AT for coagulation, IL-4 for cytokines, CXCL10 for 
chemokines, $\mathrm{C} 3 \mathrm{a}$ for complement components, sFlt-1 for angiogenesis and pentraxin-3 for inflammation.

\section{Ethics}

The Regional Ethics Committee at the University Hospital of Linköping approved this study and informed consent was given from all participants in the study.

\section{Results}

\section{Coagulation parameters}

The AT levels $(\mathrm{p}=0.002)$ were lower and APTT $(\mathrm{p}=0.019)$ levels were shorter in the preeclampsia group than in healthy controls (fig 1a,table 2). Multivariate logistic regression confirmed these associations ( $\mathrm{p}=0.02$ for AT and $\mathrm{p}=0.04$ for APTT) and also showed that the difference in AT levels was more pronounced in the EOP than in the LOP group $(p=0.006)$. Mutation for factor V Leiden was more frequent in EOP compared to controls (chi2-test, $\mathrm{p}=0.045$ ) but no difference was found between the entire preeclampsia group and controls. Cardiolipin antibodies were neither found in the index group nor in the control group and there was no difference concerning occurrence of lupus anticoagulant between preeclamptic women and women with normal pregnancy. Two cases of protrombin gene mutation were found, both of them in the LOP group. The concentrations of protein S and fibrinogen as well as INR values were similar in the preeclampsia and control group. The D-Dimer levels were increased $(p=0.001)$ while the numbers of platelets $(p=0.026)$ and the concentration of protein $\mathrm{C}$ were lower $(\mathrm{p}=0.045)$ in women with preeclampsia than in healthy controls, but with multivariate logistic regression test these significant associations disappeared. For the complete result of measurement of coagulation factors see table 2 . 

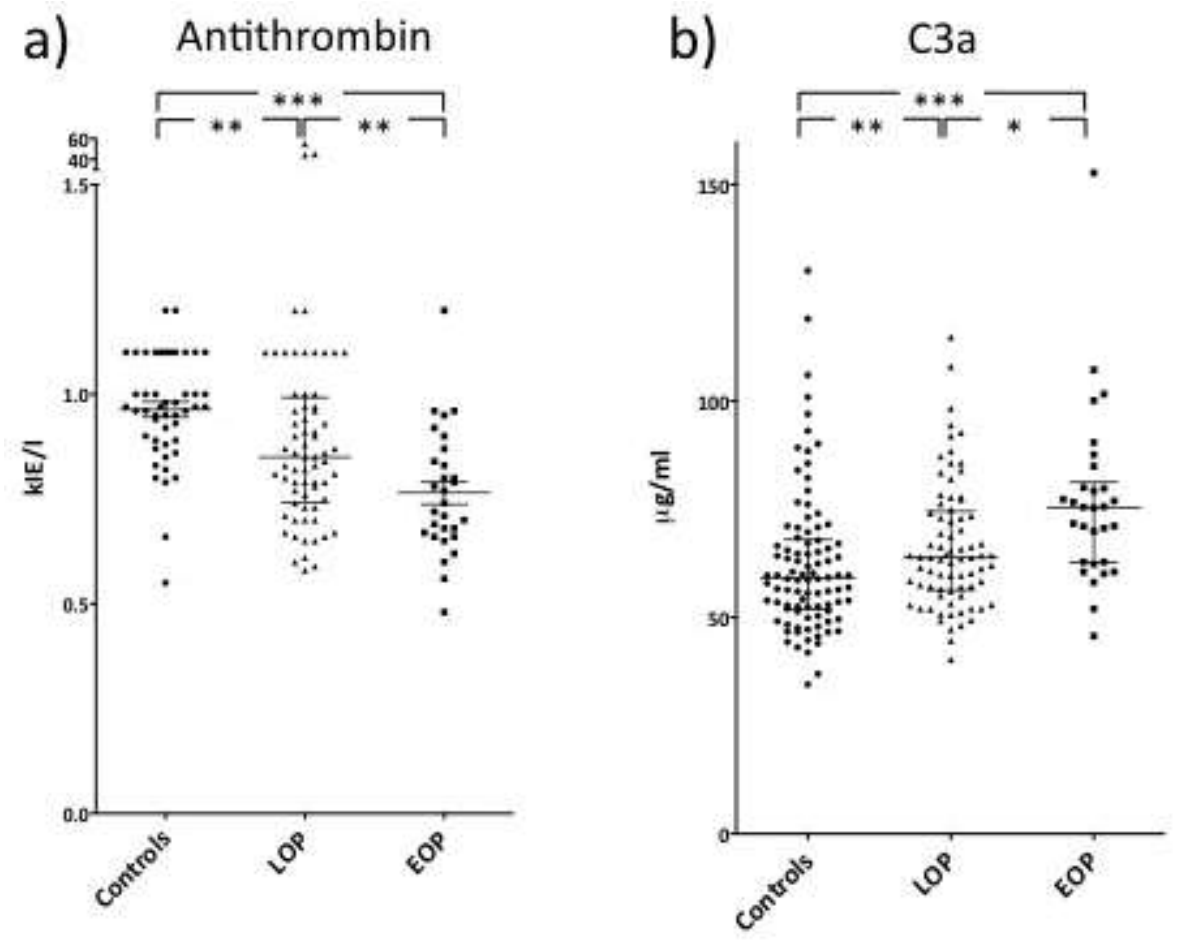

\section{Figure 1 a-b}

Plasma levels of antithrombin and C3a in women with early onset (EOP) and late onset preeclampsia (LOP) as well as in controls.

Medians and interquartile ranges are indicated.

$* \mathrm{p}<0.05, * * \mathrm{p}<0.01, * * * \mathrm{p}<0.001$. Mann-Whitney non-parametric test is used.

Analyses for antithrombin were performed on citrated plasma on an automated coagulation instrument. The complement components $\mathrm{C} 3 \mathrm{a}$ were measured by sandwich ELISA.

\section{Complement components and activation products}

The C3a levels $(\mathrm{p}<0.001)$ were elevated in the preeclampsia as compared with the control group, confirmed with multivariate logistic regression test $(\mathrm{p}=0.02)$ which also showed a more pronounced elevation in EOP ( $\mathrm{p}=0.003)$ than in LOP (fig 1b). Preeclampsia was also associated with increased sC5b-9 levels $(\mathrm{p}=0.026)$, more pronounced for $\mathrm{EOP}(\mathrm{p}=0.036)$, although these differences did not remain after multivariate logistic regression. No differences were found for $\mathrm{C} 3$ and factor $\mathrm{H}$. Data on measurements of complement components and activation products are found in table 3 . 
Table 3 Complement components and activation products, inflammation marker and angiogenesis factors.

\begin{tabular}{|l|l|l|l|}
\hline & EOP(n=30) & LOP(n=78-80) & Controls (n=94-97) \\
\hline C3 mg/L & 1326 & 1245 & 1265 \\
& $(1118-1691)$ & $(1110-1480)$ & $(1058-1460)$ \\
\hline C3a $\mathrm{gg} / \mathrm{L}$ & $75^{* * *}$ & $64 * *$ & 59 \\
& $(63-86)$ & $(56-76)$ & $(51-67)$ \\
\hline factor H mg/L & 606 & 597 & 593 \\
& $(528-703)$ & $(526-683)$ & $(554-659)$ \\
\hline C5b-9 AU/ML & $36 *$ & 28 & 25 \\
& $(26-54)$ & $(22-38)$ & $19-43$ \\
\hline pentraxin-3 pg/ml & $9122^{* * *}$ & $5938^{* * *}$ & 3249 \\
& $(4221-13519)$ & $(3222-9557)$ & $(2208-6120)$ \\
\hline sFlt-1 pg/ml & $10470 * * *$ & $5760 * * *$ & 839 \\
& $(5682-18789)$ & $(2851-9936)$ & $(368-1543)$ \\
\hline Placental Growth Factor pg/ml & $3.9 * * *$ & $13 * * *$ & 59 \\
& $(3.9-14)$ & $(3.9-31)$ & $(26-149)$ \\
\hline
\end{tabular}

Medians and interquartile ranges are indicated.

sFlt-1= soluble Fms-like thyrosine kinase 1

${ }^{*} \mathrm{p}<0.05,{ }^{* *} \mathrm{p}<0.01, * * * \mathrm{p}<0.001$ vs controls. Mann-Whitney non-parametric test is used.

The complement components $\mathrm{C} 3$ and factor $\mathrm{H}$ and the activation products $\mathrm{C} 3 \mathrm{a}$ and sC5b-9 complex were measured by sandwich ELISA. Plasma samples were analyzed using DuoSet ELISA reagents for sFlt-1, Placental Growth Factor and pentraxin-3.

\section{Inflammation markers}

\section{Cytokines}

The IL-4 levels were lower in preeclamptic than in healthy women $(\mathrm{p}=0.02)$, with a significant difference for the EOP $(\mathrm{p}=0.003)$ but not the LOP group as compared with the control group (fig 2a). Levels of GM-CSF were also lower in the EOP group while all other cytokine levels showed no difference when comparing preeclampsia and control women 
(table 4). Multivariate logistic regression test confirmed a tendency to lower levels of IL-4 in the preeclampsia group $(\mathrm{p}=0.058)$ but this was not the fact for GM-CSF. 
Table 4 Cytokines and chemokines.

\begin{tabular}{|c|c|c|c|}
\hline & $\begin{array}{l}\mathrm{EOP}(\mathrm{pg} / \mathrm{ml}) \\
(\mathrm{n}=29-30)\end{array}$ & $\begin{array}{l}\mathrm{LOP}(\mathrm{pg} / \mathrm{ml}) \\
(\mathrm{n}=80-81)\end{array}$ & $\begin{array}{l}\text { Controls }(\mathrm{pg} / \mathrm{ml}) \\
(\mathrm{n}=96-97)\end{array}$ \\
\hline $\begin{array}{l}\text { M- } \\
\text { CSFn=80- } \\
81)\end{array}$ & $\begin{array}{l}49 \\
(49-49)\end{array}$ & $\begin{array}{l}49 \\
(49-49)\end{array}$ & $\begin{array}{l}49 \\
(49-49)\end{array}$ \\
\hline GM-CSF & $\begin{array}{l}20 * \\
(13.2-35.1)\end{array}$ & $\begin{array}{l}34 \\
(15-61)\end{array}$ & $\begin{array}{l}32 \\
(20-49)\end{array}$ \\
\hline IFN- $\gamma$ & $\begin{array}{l}39 \\
(22-57)\end{array}$ & $\begin{array}{l}42 \\
(27-68)\end{array}$ & $\begin{array}{l}44 \\
(30-76)\end{array}$ \\
\hline IL-1 $\beta$ & $\begin{array}{l}0.9 \\
(0.4-1.7)\end{array}$ & $\begin{array}{l}1.0 \\
(0.5-1.6)\end{array}$ & $\begin{array}{l}1.0 \\
(0.5-1.5)\end{array}$ \\
\hline IL-2 & $\begin{array}{l}60 \\
(44-99) \\
\end{array}$ & $\begin{array}{l}74 \\
(45-122)\end{array}$ & $\begin{array}{l}69.5 \\
(44-113) \\
\end{array}$ \\
\hline IL-4 & $\begin{array}{l}29 * * \\
(18-57)\end{array}$ & $\begin{array}{l}47 \\
(24-75)\end{array}$ & $\begin{array}{l}46 \\
(31-83) \\
\end{array}$ \\
\hline IL-5 & $\begin{array}{l}6.1 \\
(4.0-10.4) \\
\end{array}$ & $\begin{array}{l}8.0 \\
(5.0-13) \\
\end{array}$ & $\begin{array}{l}7.8 \\
(5.5-13) \\
\end{array}$ \\
\hline IL-6 & $\begin{array}{l}9.7 \\
(5.3-17)\end{array}$ & $\begin{array}{l}11 \\
(6.3-20)\end{array}$ & $\begin{array}{l}11 \\
(7.2-20)\end{array}$ \\
\hline IL-8 & $\begin{array}{l}22 \\
13-31 \\
\end{array}$ & $\begin{array}{l}24 \\
(17-35) \\
\end{array}$ & $\begin{array}{l}26 \\
(18-36) \\
\end{array}$ \\
\hline IL-10 & $\begin{array}{l}9.2 \\
(5.1-13) \\
\end{array}$ & $\begin{array}{l}13 \\
(5.9-18) \\
\end{array}$ & $\begin{array}{l}11 \\
(7.0-17) \\
\end{array}$ \\
\hline TNF & $\begin{array}{l}26 \\
(14-36) \\
\end{array}$ & $\begin{array}{l}29 \\
(20-48) \\
\end{array}$ & $\begin{array}{l}31 \\
(20-52) \\
\end{array}$ \\
\hline$\overline{\text { CXCL11 }}$ & $\begin{array}{l}120^{*} \\
(81-182)\end{array}$ & $\begin{array}{l}93 \\
(62-125)\end{array}$ & $\begin{array}{l}89 \\
(65-125)\end{array}$ \\
\hline CXCL10 & $\begin{array}{l}86^{* *} \\
(62-160)\end{array}$ & $\begin{array}{l}115^{* * * *} \\
(80-161)\end{array}$ & $\begin{array}{l}70 \\
(51-99) \\
\end{array}$ \\
\hline CCL17 & $\begin{array}{l}12.0^{* * *} \\
(8.7-22)\end{array}$ & $\begin{array}{l}8.7 \\
(6.3-13)\end{array}$ & $\begin{array}{l}8.3 \\
(5.4-13)\end{array}$ \\
\hline CCL22 & $\begin{array}{l}106.6 \\
(72-142)\end{array}$ & $\begin{array}{l}97.5 \\
(67-130)\end{array}$ & $\begin{array}{l}93.4 \\
(68-117)\end{array}$ \\
\hline
\end{tabular}

Medians and interquartile ranges are indicated.

$* \mathrm{p}<0.05 . * * \mathrm{p}<0.01 . * * * \mathrm{p}<0.001$ vs controls. Mann-Whitney non-parametric test is used. GM-CSF $=$ Granulocyte Macrophage-Colony Stimulating Factor. IFN- $\gamma=$ interferon- $\gamma$. IL$1 \beta=$ interleukin $1 \beta$. IL-2- IL-10=interleukin 2-10. TNF=Tumor Necrosis Factor. CXCL11=C$\mathrm{X}-\mathrm{C}$ motif ligand 11. CXCL10=C-X-C motif chemokine 10. CCL17=C-C motif ligand 17. CCL22= C-C motif chemokine 22.

The cytokine levels were determined by multiplex bead array and the levels of chemokines were measured with an in-house multiplexed bead assay. 


\section{Pentraxin-3}

The pentraxin-3 levels were increased in the PE group compared to controls $(\mathrm{p}<0.001)$ and the levels tended to be higher in the EOP than the LOP group ( $p=0.061)$, see fig $2 \mathrm{~b}$ and table 3. Multivariate logistic regression test confirmed these associations by analysis of quartiles $(\mathrm{p}=0.001)$.

\section{Chemokines}

The levels of the Th1-associated chemokine CXCL10 $(\mathrm{p}<0.001)$ were increased in the preeclampsia group compared to controls and EOP was associated with elevated levels of the Th1-associated chemokine CXCL11, both confirmed with multivariate logistic regression test (for CXCL10 p=<0.001 and for CXCL11 p=0.038) (fig 2c-d). Although the levels of the Th2associated chemokine CCL17 were increased in the EOP group, this was not confirmed with the multivariate logistic regression test. CCL22 levels were similar in women with and without preeclampsia (see table 4).

\section{Angiogenesis factors}

There was a highly significant increase in the concentration of sFlt-1 $(\mathrm{p}<0.001)$ and decrease in PlGF $(\mathrm{p}<0.001)$ in the preeclampsia compared with the healthy control group. The differences were more pronounced in the EOP compared with the LOP group both for sFlt-1 $(p=0.003)$ and for PlGF $(p=0.012)$, see fig 3a-b and table 3 . This was confirmed with multivariate logistic regression test $(\mathrm{p}<0.001$ for $\mathrm{sFlt}-1$ and $\mathrm{p}<0.001$ for $\mathrm{PlGF}$ ).

\section{Cortisone}

Measurements of betamethasone, dexamethasone and prednisolone in plasma confirmed that 10 of 114 women had been treated with betamethasone at the time of blood sampling, all of them except one with EOP (the woman with LOP had an onset of preeclampsia in week 33). Since almost all cortisone treated women belonged to the EOP group we had to exclude the 
women treated with cortisone in the multivariate logistic regression test for EOP. Thus,

only 21 women remained for analysis in the group, and significance for differences in levels of cytokines in EOP and of some coagulation factors (protein C, D-Dimer and platelet count) in the preeclampsia group compared to healthy controls disappeared.
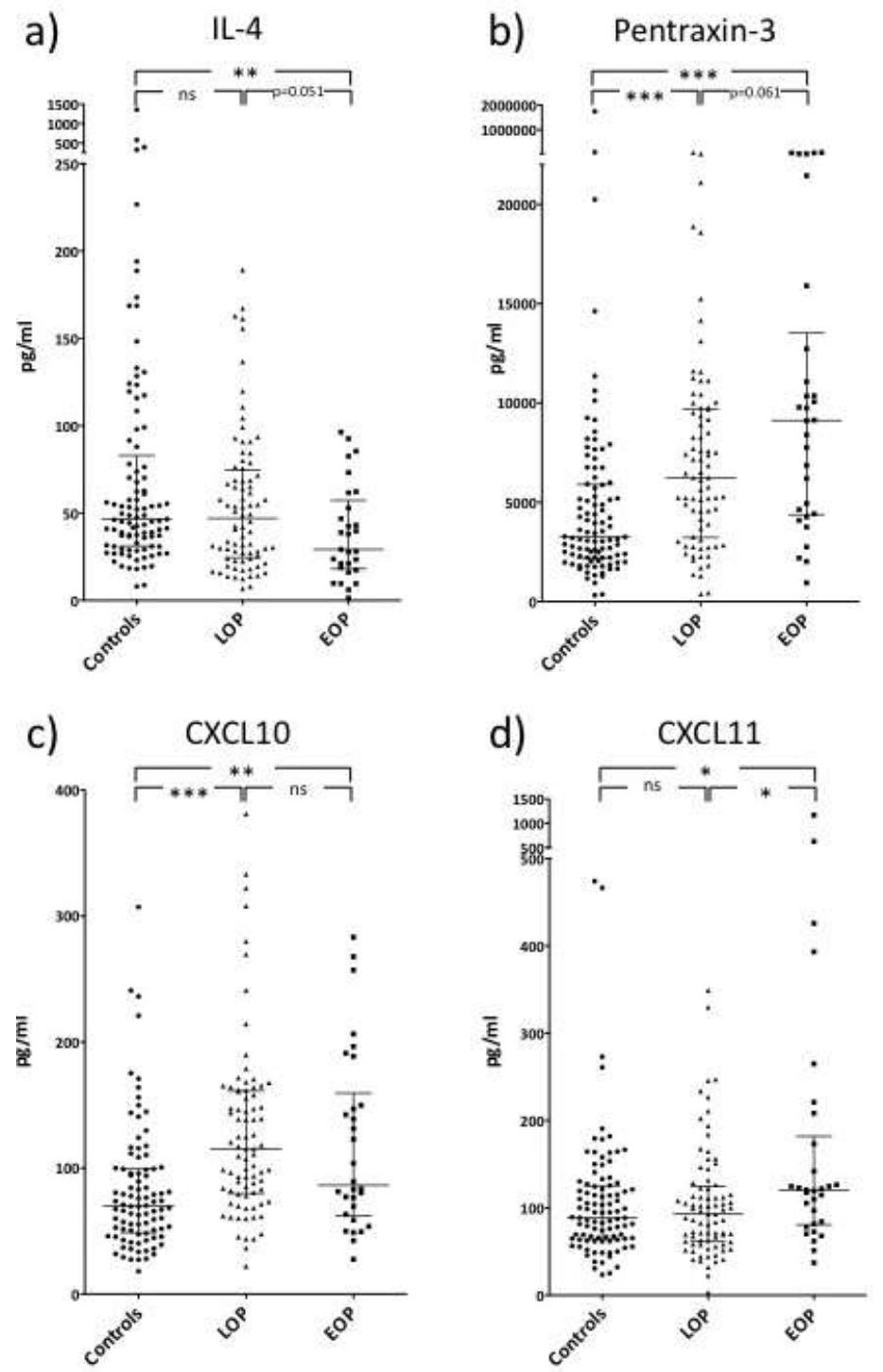

\section{Figure 2 a-d}

The plasma levels of IL-4 (a), pentraxin-3 (b), CXCL10 (c) and CXCL11 (d) in women with early onset (EOP) and late onset preeclampsia (LOP) as well as controls.

Medians and interquartile ranges are indicated.

${ }^{*} \mathrm{p}<0.05, * * \mathrm{p}<0.01, * * * \mathrm{p}<0.001$. Mann-Whitney non-parametric test is used.

The cytokine levels were determined by multiplex bead array and the levels of chemokines were measured with an in-house multiplexed bead assay. Plasma samples were analyzed using DuoSet ELISA reagents for pentraxin-3. 

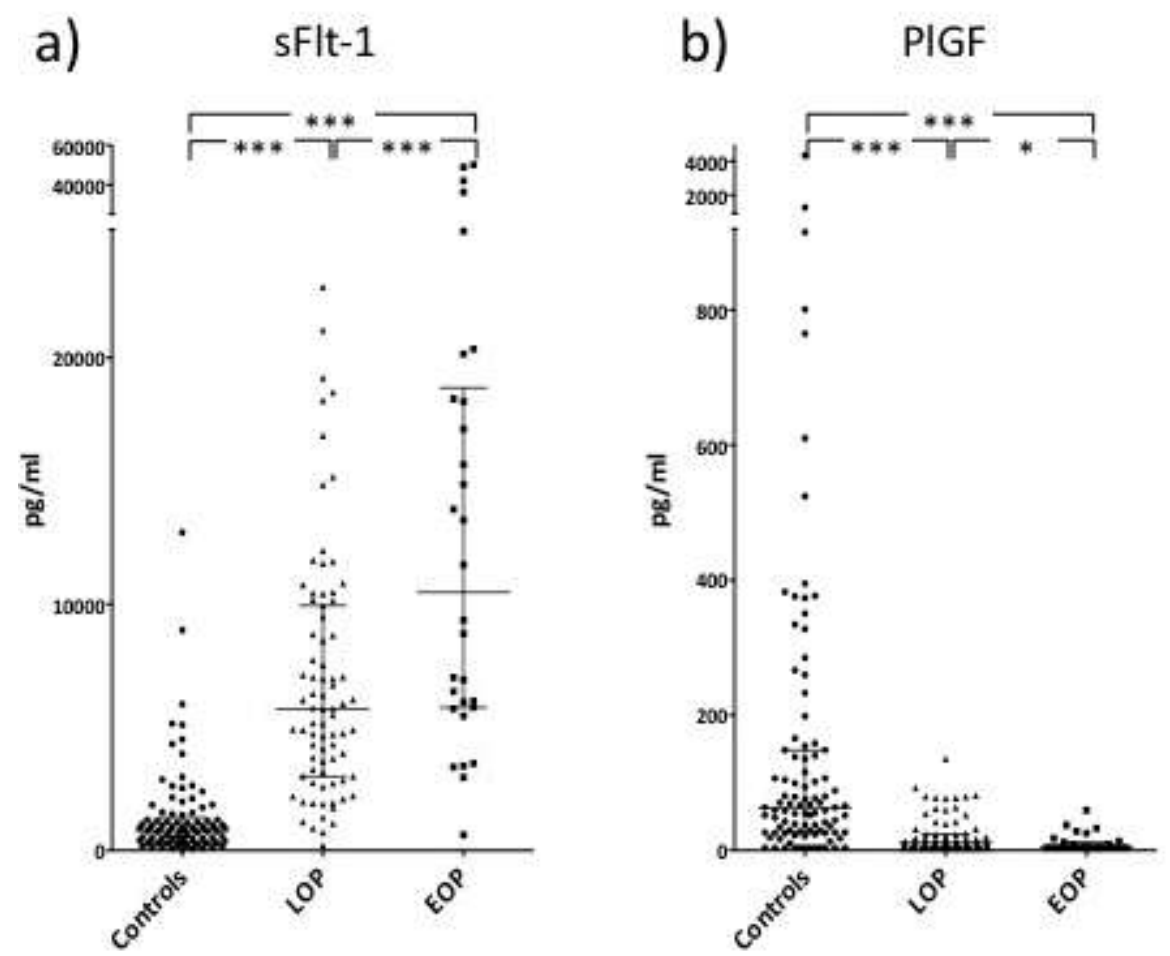

Figure 3 a-b

The plasma s-Flt levels (a) and the PIGF levels (b) in early onset (EOP) and late onset preeclampsia (LOP) as well as in controls. Medians and interquartile ranges are indicated. $* \mathrm{p}<0.05, * * \mathrm{p}<0.01, * * * \mathrm{p}<0.001$. Mann-Whitney non-parametric test is used. sflt- $1=$ soluble fms-like thyrosine kinase 1, PlGF=Placental Growth Factor. Plasma samples were analyzed using DuoSet ELISA reagents for sflt-1 and PIGF

\section{Stratified analysis for parity}

Preeclampsia was associated with reduced levels of the coagulation factor AT in both nulliparous and multiparous women ( $\mathrm{p}<0.001$ for both groups).

For complement components and activation products, the levels were similar in the preeclampsia group and the control group for multiparous women, but for nulliparous women the levels of $\mathrm{C} 3 \mathrm{a}(\mathrm{p}=0.001)$ and $\mathrm{TCC}(\mathrm{p}=0.034)$ were elevated as well as the $\mathrm{C} 3 \mathrm{a} / \mathrm{C} 3$ ratio $(\mathrm{p}=0.02)$ in the preeclampsia group. There was also a tendency to elevated levels of factor $\mathrm{H}$ $(\mathrm{p}=0.059)$.

For chemokines, the CCXL10 levels were more dramatically elevated in nulliparous $(\mathrm{p}<0.001)$ than in multiparous women $(\mathrm{p}=0.048)$ for preeclampsia compared with controls. 
Analysis of cytokines showed no differences between the preeclampsia and control group for multiparous women but for nulliparous women IL-4 ( $p=0.005)$, were lower in the preeclampsia group. Also, the pentraxin-3 levels were higher in the preeclampsia group than in controls among multiparous $(\mathrm{p}=0.004)$ but not nulliparous women $(\mathrm{p}=0.096)$. For the angiogenesis factors, the PIGF levels were lower $(\mathrm{p}<0.001)$ and the sFlt-1 levels were higher $(\mathrm{p}<0.001)$ in the preeclampsia group than the control group for both nulliparous and multiparous women.

\section{Correlations}

Correlation tests were done to compare selected markers for coagulation, inflammation and angiogenesis. AT, C3a, IL-4, CXCL10, pentraxin-3, sFlt-1 and PlGF were used. We choose the marker in each group (coagulation factors, complement, cytokines, chemokines, inflammation and angiogenesis markers), which showed the most significant association, which also remained after multiple logistic regression.

The correlation coefficients (rho) between these markers ranged from -0.18 to 0.27 in the preeclampsia group. The strength of the correlations were even smaller when subgroup analysis for EOP and LOP was done.

\section{SGA (Small for Gestational Age)}

A subgroup analysis was also done for women who gave birth to SGA and AGA (Appropriate for Gestational Age) babies. Levels of s-Flt were increased $(\mathrm{p}=0.006)$ and for PlGF decreased $(\mathrm{p}=0.013)$ in case of SGA, but for cytokines, chemokines, pentraxin-3, complement components and activation products, there were no differences between the two groups. All these women were in the preeclampsia group. 


\section{Discussion}

We here demonstrate that markers for activated coagulation, inflammation and aberrant angiogenesis are associated with preeclampsia. Notably, these factors were not intercorrelated in preeclampsia, suggesting that they reflect different parts or phases of the pathogenesis. By simultaneously comparing several systems, we could show that preeclampsia was particularly associated with angiogenic factors and a Th1-associated chemokine and complement activation profile, whereas cytokines showed weaker associations.

Preeclampsia is known as a syndrome of systemic inflammation $(8,20)$, which was also demonstrated in this study by increased levels of complement activation products, pentraxin-3 and pro-inflammatory chemokines. Several studies have demonstrated a shift from Th2 to Th1 in preeclampsia with an increase of pro-inflammatory and a decrease of antiinflammatory cytokines $(12,21-23)$. We failed to demonstrate this suggested shift by mere cytokine analysis, although levels of the Th2 cytokine IL-4 were decreased in preeclamptic women. However, by chemokine analysis a shift was obvious towards a predominant inflammatory activity, with elevated levels of two Th1-associated and no clear increase in two Th2-associated chemokines in the preeclampsia group. Circulating Th1- and Th2-associated chemokine levels can be used as markers for the Th1/Th2 balance (24-26). Thus, Th1 responses increase the levels of the CXCR3 ligands CXCL10 and CXCL11, while Th2 responses enhance the levels of the CCR4 ligands CCL17 and CCL22 $(27,28)$. CXCR3 is preferentially expressed on Th1 cells and CCR4 on Th2 cells, thus further amplifying Th1 and Th2 immunity, respectively (27). Although several previous studies by us and by others have shown a Th1-like pattern of cytokines in preeclampsia, some of them have been rather small and in general they were not controlled for gestational age and cortisone treatment, commonly used in EOP $(12,21,29-32)$. As other studies have failed to show differences in levels of 
cytokines between normotensive and pre-eclamptic pregnancies $(20,33,34)$, the previous results are inconsistent. There might also be a publishing bias for studies showing this Th1/Th2-cytokine shift. Cytokines could also be difficult to measure in the circulation since their function is mainly in paracrine interactions between cells in different tissues whereas chemokines also mediate effects over longer distances. Thus, chemokines might be more suitable markers for immunological changes during pregnancy and for preeclampsia due to their stability and presence in higher levels in the circulation, whereas circulating levels of cytokines seem less useful for monitoring preeclampsia. This has, however, to be proved by multiple evaluations throughout pregnancy. Furthermore, local cytokine levels at the maternal-fetal interface are likely strongly associated with preeclampsia, although not reflected in the circulation.

Inflammation and coagulation are closely integrated and we could demonstrate that also the coagulation system was activated in preeclampsia. Thus, the levels of most of the anticoagulation factors were decreased in the preeclampsia group, regardless of parity mostly pronounced for AT, and presumably an increase of some coagulation factors resulted in a shortened APTT. Furthermore, the prevalence of the inherited factor V Leiden mutation was also increased in women with EOP. Thus, it seems that activated coagulation is a part of the pathophysiology involved in the development of clinically manifest preeclampsia and that inherited thrombophilia might be a risk factor for pathological placentation. Our expected high correlation between AT as a marker for activated coagulation and inflammation markers as pentraxin-3 and Th1-related CXCL10 was not corroborated. Therefore, the activated coagulation found in preeclampsia may be at least in part an independent pathogenic mechanism and not only a mirror of the systemic inflammation, at least at the time point investigated in this study. 
The increased concentration of $\mathrm{C} 3 \mathrm{a}$ and $\mathrm{sC} 5 \mathrm{~b}-9$ in preeclamptic compared to healthy women demonstrates that also the complement system is involved in the inflammatory reaction in preeclampsia. Since the first step in the generation of $\mathrm{sC} 5 \mathrm{~b}-9$ is the cleavage of $\mathrm{C} 5$ to $\mathrm{C} 5 \mathrm{a}$ and $\mathrm{C} 5 \mathrm{~b}$, this observation is in agreement with others who have suggested that C5a-dependent mechanisms might be of interest in placental pathology in preeclampsia $(35,36)$. In the stratified analysis the activation of the complement system could only be demonstrated for nulliparous women. In agreement with the cytokine, chemokine and pentraxin-3 data, this might indicate less intense inflammatory response in multiparous compared to nulliparous women, possibly related to immune regulatory effects of previous pregnancies. In accordance with several previous studies, we found a highly significant increase in the anti-angiogenic factor sFlt-1 and decrease of the pro-angiogenic factor P1GF in women with preeclampsia, both for nulliparous and multiparous women $(5,37,38)$. However, no obvious correlation was found between these factors and markers for coagulation and inflammation, suggesting that these pathogenic mechanisms are in part independent or separated in time.

EOP was associated with more pronounced differences in the levels of almost all of these markers of hypercoagulation, inflammation and aberrant angiogenesis as compared with LOP. Thus, EOP might be a more homogenous condition based on placental pathology. In LOP, there might be an increased sensitivity of the maternal endothelium and a less pronounced placental pathology (7). In women giving birth to SGA babies, where a pathologic placentation can be anticipated, we found no differences in levels of examined biomarkers except for sFlt-1 and PlGF. Thus, these biomarkers seem to be good indicators of placental pathology, while other biomarkers might as well indicate maternal endothelial pathology. The strength of this study is the large sample and that a substantial part of preeclamptic women in a specific region were involved in the study. The described mechanisms have each been studied separately by others, but never simultaneously in the same sample, thus giving 
us the possibility to analyze the relative contribution and correlation between these mechanisms. In contrast to previous studies, the results of the analyses were controlled by multivariate logistic regression for maternal and gestational age, peripartal blood sampling and steroid treatment, which all might influence the result. Since the pathogenesis for EOP and LOP might differ, subgroup analyses of these conditions are valuable.

Limitations of this study include that samples were drawn from a quite homogenous population with an internationally low prevalence of preeclampsia. The prevalence of both preeclampsia and congenital thrombophilia differ between different regions for hereditary or other reasons. Also, the correlations between the described mechanisms may be temporally displaced. Thus, correlations might not be apparent by measurement of these biomarkers at a particular moment. Also, the cross-sectional design does not allow conclusions regarding causal relationships.

In conclusion, markers for hypercoagulation, increased inflammation and aberrant angiogenesis were independently associated with preeclampsia. Cytokines, chemokines and complement factors seem to be part of a Th1-associated inflammatory reaction in preeclampsia. Most of the differences were more pronounced for EOP than for LOP suggesting a more homogeneous pathogenesis in EOP. Chemokines, in contrast to cytokines, may prove to be useful markers in preeclampsia, in addition to established markers. 


\section{Acknowledgement}

This study was financially supported by FORSS (Medical Research Council of Southeast Sweden), Futurum (the Research department of County of Jönköping), the Swedish Research Council Grant 2007-15809-48800-58, and by faculty grants from the Linneaus university (Sweden). The authors are grateful to the committed staff at the County Hospital Ryhov in Jönköping, the University Hospital in Linköping and at antenatal health centers for their assistance in recruiting women to the study and collecting blood samples. Anne-Marie Fornander, Jennie Röjdner and Anna Forsberg are acknowledged for excellent technical assistance in laboratory analysis work. Mats Fredriksson at Linköping Academic Research Centre (LARC) has with his statistical analyses given a great contribution to this work. 


\section{References}

1.Duley L. The global impact of pre-eclampsia and eclampsia. Semin Perinatol 2009 Jun;33(3):130-7.

2.Matthiesen L, Berg G, Ernerudh J, Ekerfelt C, Jonsson Y, Sharma S. Immunology of preeclampsia. Chem Immunol Allergy 2005;89:49-61.

3.Redman CW. Immunology of preeclampsia. Semin Perinatol 1991 Jun;15(3):257-62.

4.Redman CW, Sargent IL. Immunology of pre-eclampsia. Am J Reprod Immunol Jun;63(6):534-43.

5.Wikstrom AK, Larsson A, Eriksson UJ, Nash P, Norden-Lindeberg S, Olovsson M.

Placental growth factor and soluble FMS-like tyrosine kinase-1 in early-onset and late-onset preeclampsia. Obstet Gynecol 2007 Jun;109(6):1368-74.

6. Valensise H, Vasapollo B, Gagliardi G, Novelli GP. Early and late preeclampsia: two different maternal hemodynamic states in the latent phase of the disease. Hypertension 2008 Nov;52(5):873-80.

7.Vatten LJ, Skjaerven R. Is pre-eclampsia more than one disease? BJOG 2004 Apr;111(4):298-302.

8.Redman CW, Sacks GP, Sargent IL. Preeclampsia: an excessive maternal inflammatory response to pregnancy. Am J Obstet Gynecol 1999 Feb;180(2 Pt 1):499-506.

9.Alfirevic Z, Roberts D, Martlew V. How strong is the association between maternal thrombophilia and adverse pregnancy outcome? A systematic review. Eur J Obstet Gynecol Reprod Biol 2002 Feb 10;101(1):6-14.

10.Jonsson Y, Ekerfelt C, Berg G, Nieminen K, Sharma S, Ernerudh J, et al. Systemic Th1/Th2 cytokine responses to paternal and vaccination antigens in preeclampsia: no differences compared with normal pregnancy. Am J Reprod Immunol 2004 Apr;51(4):302-10. 11.Lin J, August P. Genetic thrombophilias and preeclampsia: a meta-analysis. Obstet Gynecol 2005 Jan;105(1):182-92.

12.Jonsson Y, Ruber M, Matthiesen L, Berg G, Nieminen K, Sharma S, et al. Cytokine mapping of sera from women with preeclampsia and normal pregnancies. J Reprod Immunol 2006 Jun;70(1-2):83-91.

13.ACOG practice bulletin. Diagnosis and management of preeclampsia and eclampsia. Number 33, January 2002. Obstet Gynecol 2002 Jan;99(1):159-67.

14.Enstrom C, Osman A, Lindahl TL. A genotyping method for VKORC1 1173C > T by Pyrosequencing technology. Scand J Clin Lab Invest 2008;68(5):427-30.

15.Nilsson Ekdahl K, Nilsson B, Pekna M, Nilsson UR. Generation of iC3 at the interface between blood and gas. Scand J Immunol 1992 Jan;35(1):85-91.

16. Mollnes TE, Lea T, Froland SS, Harboe M. Quantification of the terminal complement complex in human plasma by an enzyme-linked immunosorbent assay based on monoclonal antibodies against a neoantigen of the complex. Scand J Immunol 1985 Aug;22(2):197-202. 17.Henningsson AJ, Ernerudh J, Sandholm K, Carlsson SA, Granlund H, Jansson C, et al. Complement activation in Lyme neuroborreliosis--increased levels of $\mathrm{C} 1 \mathrm{q}$ and $\mathrm{C} 3 \mathrm{a}$ in cerebrospinal fluid indicate complement activation in the CNS. J Neuroimmunol 2007 Feb;183(1-2):200-7.

18.Furuhjelm C, Jenmalm MC, Falth-Magnusson K, Duchen K. Th1 and Th2 Chemokines, Vaccine-Induced Immunity, and Allergic Disease in Infants After Maternal omega-3 Fatty Acid Supplementation During Pregnancy and Lactation. Pediatr Res Mar;69(3):259-64. 19.Palonek E ÖF, Garle M, Screening for corticosteroids in urine with on-line extraction and LC-MSMS detection. Recent Advances in Doping Analysis (13), Sportverlag Strauss - Köln 2005, 47 - 56 Screening for corticosteroids in urine with on-line extraction and LC-MSMS 
detection. Recent Advances in Doping Analysis. Sportverlag Strauss - Köln 2005(2005):47 56

20.Freeman DJ, McManus F, Brown EA, Cherry L, Norrie J, Ramsay JE, et al. Short- and long-term changes in plasma inflammatory markers associated with preeclampsia. Hypertension 2004 Nov;44(5):708-14.

21.Tosun M, Celik H, Avci B, Yavuz E, Alper T, Malatyalioglu E. Maternal and umbilical serum levels of interleukin-6, interleukin-8, and tumor necrosis factor-alpha in normal pregnancies and in pregnancies complicated by preeclampsia. J Matern Fetal Neonatal Med Aug;23(8):880-6.

22.Madazli R, Aydin S, Uludag S, Vildan O, Tolun N. Maternal plasma levels of cytokines in normal and preeclamptic pregnancies and their relationship with diastolic blood pressure and fibronectin levels. Acta Obstet Gynecol Scand 2003 Sep;82(9):797-802.

23. Guven MA, Coskun A, Ertas IE, Aral M, Zencirci B, Oksuz H. Association of maternal serum CRP, IL-6, TNF-alpha, homocysteine, folic acid and vitamin B12 levels with the severity of preeclampsia and fetal birth weight. Hypertens Pregnancy 2009 May;28(2):190200.

24.Miotto D, Christodoulopoulos P, Olivenstein R, Taha R, Cameron L, Tsicopoulos A, et al. Expression of IFN-gamma-inducible protein; monocyte chemotactic proteins 1, 3, and 4; and eotaxin in TH1- and TH2-mediated lung diseases. J Allergy Clin Immunol 2001 Apr;107(4):664-70.

25.Sandberg M, Frykman A, Ernerudh J, Berg G, Matthiesen L, Ekerfelt C, et al. Cord blood cytokines and chemokines and development of allergic disease. Pediatr Allergy Immunol 2009 Sep;20(6):519-27.

26.Stumpf C, Auer C, Yilmaz A, Lewczuk P, Klinghammer L, Schneider M, et al. Serum levels of the Th1 chemoattractant interferon-gamma-inducible protein (IP) 10 are elevated in patients with essential hypertension. Hypertens Res 2011 Apr;34(4):484-8.

27.Pease JE, Williams TJ. Chemokines and their receptors in allergic disease. J Allergy Clin Immunol 2006 Aug;118(2):305-18; quiz 19-20.

28. Mantovani A, Sica A, Sozzani S, Allavena P, Vecchi A, Locati M. The chemokine system in diverse forms of macrophage activation and polarization. Trends Immunol 2004 Dec;25(12):677-86.

29.Kronborg CS, Gjedsted J, Vittinghus E, Hansen TK, Allen J, Knudsen UB. Longitudinal measurement of cytokines in pre-eclamptic and normotensive pregnancies. Acta Obstet Gynecol Scand Jul;90(7):791-6.

30.Kocyigit Y, Atamer Y, Atamer A, Tuzcu A, Akkus Z. Changes in serum levels of leptin, cytokines and lipoprotein in pre-eclamptic and normotensive pregnant women. Gynecol Endocrinol 2004 Nov;19(5):267-73.

31.Kalinderis M, Papanikolaou A, Kalinderi K, Ioannidou E, Giannoulis C, Karagiannis V, et al. Elevated Serum Levels of Interleukin-6, Interleukin-1beta and Human Chorionic Gonadotropin in Pre-eclampsia. Am J Reprod Immunol May 30.

32.Kauma S, Takacs P, Scordalakes C, Walsh S, Green K, Peng T. Increased endothelial monocyte chemoattractant protein-1 and interleukin-8 in preeclampsia. Obstet Gynecol 2002 Oct;100(4):706-14.

33.Hayashi M, Ueda Y, Ohkura T, Inaba N. Interleukin-6 concentrations in the placenta and blood in normal pregnancies and preeclampsia. Horm Metab Res 2005 Jul;37(7):419-24. 34.Djurovic S, Clausen T, Wergeland R, Brosstad F, Berg K, Henriksen T. Absence of enhanced systemic inflammatory response at 18 weeks of gestation in women with subsequent pre-eclampsia. BJOG 2002 Jul;109(7):759-64. 
35.Rampersad R, Barton A, Sadovsky Y, Nelson DM. The C5b-9 membrane attack complex of complement activation localizes to villous trophoblast injury in vivo and modulates human trophoblast function in vitro. Placenta 2008 Oct;29(10):855-61.

36. Haeger M, Unander M, Bengtsson A. Complement activation in relation to development of preeclampsia. Obstet Gynecol 1991 Jul;78(1):46-9.

37.Varughese B, Bhatla N, Kumar R, Dwivedi SN, Dhingra R. Circulating angiogenic factors in pregnancies complicated by pre-eclampsia. Natl Med J India Mar-Apr;23(2):77-81.

38. Noori M, Donald AE, Angelakopoulou A, Hingorani AD, Williams DJ. Prospective study of placental angiogenic factors and maternal vascular function before and after preeclampsia and gestational hypertension. Circulation Aug 3;122(5):478-87. 